\title{
The Research of Design Method of Building Structure Based on BIM
}

\author{
Yuan XIN \\ School of Civil Engineering \\ Shenyang Jianzhu University \\ Shenyang, China \\ e-mail: 704530870@qq.com
}

\begin{abstract}
This paper discusses the building design process based on BIM platform, and analyzes the seismic analysis and design method of the structure based on BIM platform; Compared with the conventional structural design method and the design method based on BIM, the advantages of the BIM design method are analyzed, and the reference is provided for the structural engineers to use the BIM tool to carry on the structural design.
\end{abstract}

\section{Keywords-BIM; structure design; revit; anti-seismic; YJK}

\section{INTRODUCTION}

In recent years, with the speeding up of the economic and social rapid growth and the pace of urbanization, more and more residential complex building and overrun high commercial complex building rises straight from the ground [1]. Along with the changing of the architectural structure and the structural form of the building structure, there are more and more limitations in the expression of the twodimensional expression in architecture and structure. At the same time, the boring plane construction plan makes the design of the architectural engineering project in the downstream professional designers can not accurately grasp the architect's design intent. However, in the process of building engineering, design drawings throughout the project from design to construction of the termination of life cycle process, construction, operation and maintenance of the building plays an important role.

As an extension of the application technology of mechanical industry in the construction industry, BIM provides a new technology for the information management and communication of the construction project. BIM Technology not only for provides an effective way to improve the quality of construction and design drawings, also makes the model building and design information transmission in the process of building life cycle better, fundamentally solves at each stage of the design, construction, operation and maintenance of information circulation problems [2].

\section{PROBLEMS IN STRUCTURAL DESIGN}

With the BIM concept and BIM tools in architectural design, and constantly promote, based on BIM tools of the architectural design of the program and special-shaped complex structure in the form of the building is more and more, the building structure designer, architect and engineer how to co design put forward higher requirements.

\section{BIM PLATFORM STRUCTURE PROFESSIONAL SOFTWARE}

In the stage of architectural design, structural design and architectural design are closely related. In addition to the need to establish a structural model and other professional collision analysis, the structure is more focused on the calculation and analysis of the seismic performance of the structure. According to the function of the structure design, the main functions are divided into three categories:

\section{A. Structural Modeling Software}

Structural modeling software is the core modeling software, which is mainly used in the structural model of the flexible structure under the outline of the force components, the initial formation of the main structure of the building model. For civilian residential and commercial construction commonly used Revit structure software, large-scale industrial construction commonly used Bentley structure software.

\section{B. Structural Analysis Software}

Based on the characteristics of information sharing platform in BIM, the structure analysis software of BIM platform must be able to undertake the structure information model of BIM core modeling software. According to the structural analysis software, the adjustment of the structure model can also be successfully fed back to the core modeling software. At present, there is little BIM core modeling software to achieve software structure geometry model, load model and boundary constraint interaction. To achieve information geometric model, load model and boundary constraint conditions the transconductance of the software is based on the same series of software. Such as Autodesk revit structure software and Autodesk Company dedicated to the structural finite element analysis software Autodesk Robot Structural Analysis in the geometric model between the load model and the boundary constraints of the data exchange between the basic no more errors. In the domestic, Robot in structural analysis and design of Shanghai Lupu Bridge, Lu Yang bridge, Shenzhen Yantian terminal engineering, Shanghai Metro, Guangzhou Metro multiple each country large-scale construction projects are analyzed. Shanghai ocean aquarium, bank building, Shenzhen City Plaza, Nanning International Convention and Exhibition Center, 
such as the quality of curtain wall structural analysis also has the outstanding performance of Robot Structural .But because of Robot lack of the corresponding Chinese structural design code, it is difficult to popularize in the field of civil building structure analysis.

Other common software can also realize the exchange of structural data information at different depths such as ETABS, Sup2000, Midas and the general structure analysis software PKPM and so on.

\section{Structure Construction Plans to Deepen the Design Software}

The Structure construction drawing deepen design software is mainly on the node of steel structure and the complex space structure parts in specially made construction details. Began in 1990s Tekla company product Tekla structure (Xsteel) software began to quickly apply to the design of steel structure. The software for steel structure construction and hoisting process in the detailed design part automatically generate construction details, material statistics and so on. Xsteel software also supports the detailed design of concrete pre products, and its open interface can be realized with the structural finite element analysis software for information exchange. Table I. compares the difference between AutoCAD and TeKla structure function and the design in detail.

TABLE I. COMPARISON OF AUTOCAD AND TEKLAR SOFTware USING FUNCTION

\begin{tabular}{|c|c|c|c|c|c|}
\hline $\begin{array}{c}\text { Details of the } \\
\text { software }\end{array}$ & $\begin{array}{c}\text { Display } \\
\text { model }\end{array}$ & $\begin{array}{c}\text { Construction } \\
\text { plans }\end{array}$ & $\begin{array}{c}\text { Paramete } \\
\text { rization }\end{array}$ & $\begin{array}{c}\text { Material } \\
\text { library }\end{array}$ & $\begin{array}{c}\text { Collision } \\
\text { analysis }\end{array}$ \\
\hline AutoCAD & $\begin{array}{c}\text { Two- } \\
\text { dimension } \\
\text { al plane }\end{array}$ & $\begin{array}{c}\text { Point line } \\
\text { drawing }\end{array}$ & $\begin{array}{c}\text { Do not } \\
\text { Support }\end{array}$ & no & infeasible \\
\hline Xsteel & $\begin{array}{c}\text { Three } \\
\text { dimension } \\
\text { al plane }\end{array}$ & $\begin{array}{c}\text { Automatically } \\
\text { generated }\end{array}$ & Support & yes & feasible \\
\hline
\end{tabular}

\section{DESIGN Flow OF CONSTRUCTION PROJECT BASED ON BIM}

At present, in some large domestic public facilities construction, has successfully realized the successful application of 3D design (especially the 2008 Olympic project 3D design), the architectural design industry promote the development of technology.BIM will be the second time since the last century, the Off board project in 90s, the reform of architectural design. Compared with the traditional architectural design method based on BIM, it's characterized by the professional engineers do not need to go to a pile of simple and a variety of two plan to imagine the construction of a three-dimensional map. It is also no need to repeatedly compare and calculate the architectural design information, but the computer software technology in the virtual threedimensional space in the layout of components and design information. According to the understanding of the current BIM platform software, this paper attempts to establish the design process of BIM building structure in the design stage, as shown in figure 1 .

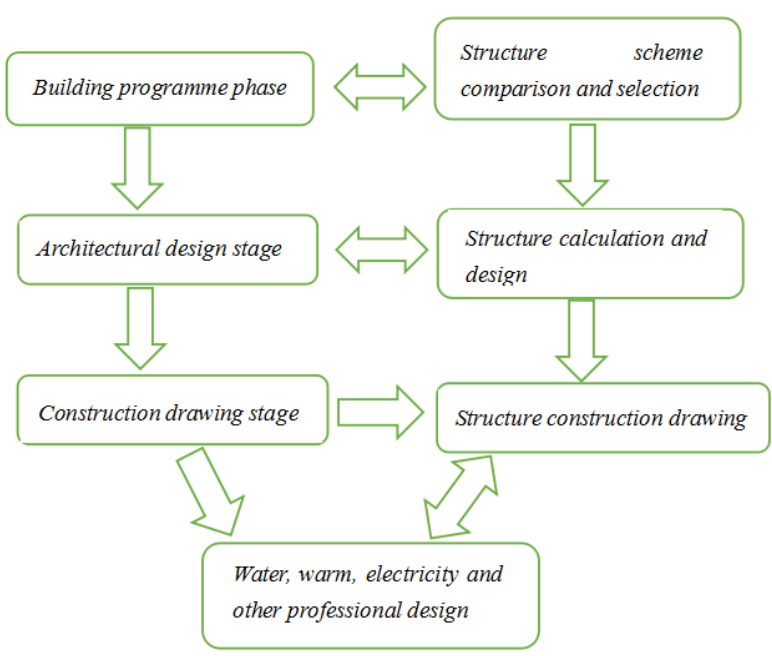

Figure 1. Construction engineering design process based on BIM platform

\section{SeISMic ANAlysis Method of StRUCtURE BASED ON REVIT STRUCTURE SOFTWARE}

Structural design as an important part of the design phase of the construction project, in the construction of safety, cost budget has played a decisive role. This section attempts to establish the BIM core modeling tool Revit series software structure seismic analysis method, the design process and the corresponding design tool software, as shown in Figure 2.

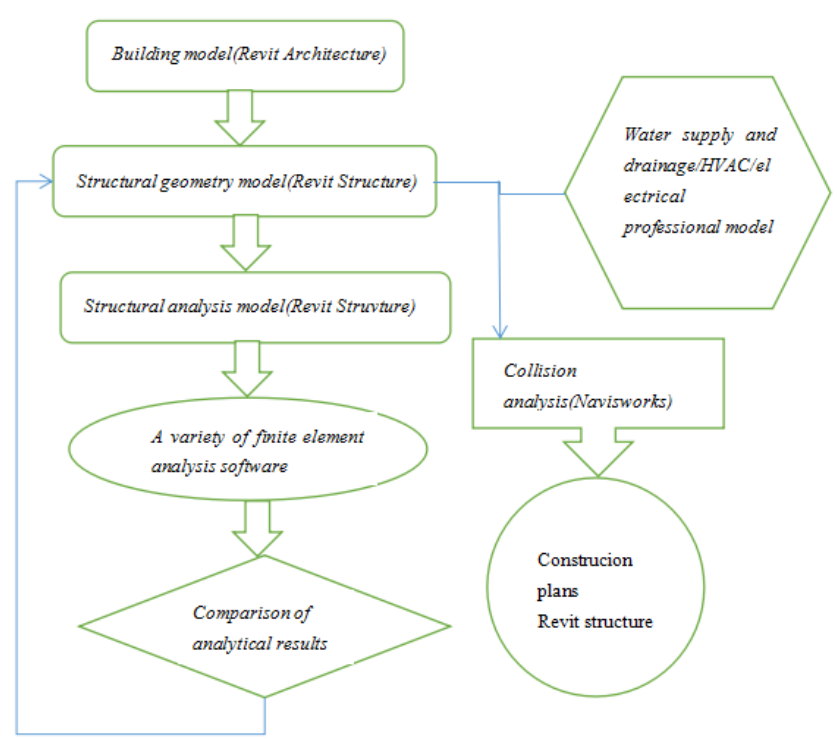

Figure 2. Seismic design method of structure based on Revit series software

\section{A. Structural Modeling Features of R Software}

In many BIM core modeling software, Autodesk Revit series software is the most widely used, and its modeling method for civil building is supported by many users. Revit series software not only supports the building information model, but also can automatically generate the design drawings, detail tables and engineering quantity calculation. 
The Revit model can provide information about the project plan, scope, quantity and stage of the project participants, as the structure module of Revit platform.

Revit Structure software has powerful modeling function, including load model, boundary condition and working condition. And RKPM, YJK, SUP2000, Midas and other analytical software modeling methods and the characteristics of the map has a lot of different.

\section{1) Working set model:}

Revit Structure software modeling can be set through the working set of the project work completed each set break up the whole into parts, the modeling work of the project. Revit platform in each work set to work independently, using the common center file of the project and coordinate system. The rights of each work set are owned by each work set, and need to be obtained from each other when the other party needs to modify the content of the other work. For a model that has been saved to the central file, the system will be updated to the corresponding working set when a design change occurs.

According to the project experience in practice, the author puts forward the following proposals:

- According to the project primary and secondary structure (main building, annex).

- According to the simple division of components (Construct family, Architecture subject).

- According to the building floor or the construction stage division (Underground part, above ground part).

- In the plane, according to the temperature seam, seismic joints, settlement joints, such as construction technology division.

- According to the structure of the use of materials (Steel structure part, Concrete part).

2) Parameter association:

Revit Structure software will be designed plan; elevation, profile and material detail table are focused on the structural model of the processing. Three dimensional model, construction drawing and material table three are related to each other. For example, the layout of a column in the plane view, the construction plans and materials statistics table will appear in the corresponding column. List is generated by the Revit software automatically generated by the. This parameter driven model allows the architect to focus on energy and model processing and computational analysis, and also to modify the design changes to be simple and efficient.

3) Analysis model:

Revit models the component in the model as a model element, which is created by a different group of people. An initial analysis model consistent with the geometric model is created in the same time. In the R structure analysis model, the load, the load combination, the size of the component, and the boundary constraint conditions of each component can be exactly set. The family is divided into the system, the internal and the family.

System family is a class of Revit in the family, the method from the external load, it cannot be saved to the outside, but it can be copied and modified in the system, to meet the requirements of the new type.

Built in order to meet the needs of special components in the current project, in other projects do not need to use the family file. Family is the family of the project needs to be loaded into the project from the outside world. Can be loaded in the form of an independent family file. Installed Revit Structure software generally have their own can be loaded into the family, the family can also copy or modify the application of other major projects.

When the structure of beams, plates and columns is arranged by the system family files, the boundary conditions of these components can be set up in the model of knowledge map, as shown in figure 3.

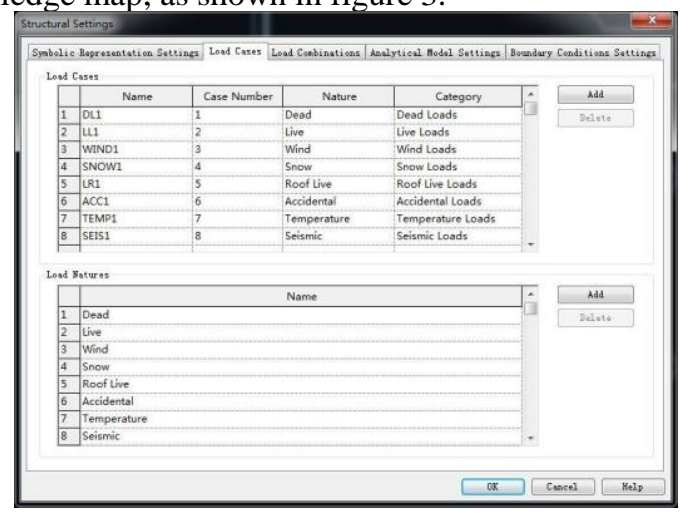

Figure 3. Revit structure load and boundary conditions set interface

\section{B. Data Exchange between Revit Software and Structural Analysis Finite Element Software}

Revit Structure software is the same as the majority of BIM software is based on the structure of the IFC standard model software. The information management in BIM adopts IFC standard as the data exchange standard of building information. In theory, the model based on IFC standard can be used to exchange data between different software by IFC standard. But in fact through the author of a large number of literature research and software comparison using the results showed that: The information transfer and sharing between the software and the structural finite element software is still limited by the structure model based on the IFC standard. Based on IFC standard, Liu Zhaoqiu, Zhang Jiantao developed a data conversion interface and PKPM structure model, but it can only achieve a rough two of the geometry, material and other information conversion, the conversion of the model there is a lot of information loss phenomenon. This kind of conversion interface still has very big limitation in the practical application. Based on the author's investigation and practice, it has been proved that the conversion interface between SATWE, ETABS, SAP2000 and other software and IFC standard has been realized. The data can be converted to a simple geometry, material and other information, as shown in table II, and most of the data between the software transfer directions is a single direction. The research and application of IFC standards in the field of architectural design and construction are relatively rich, but the lack of structural analysis. 
Although the IFC standard has been equipped with the ability to add the basic structure of the data analysis, but its application is still in the trial stage, Table II is the IFC model of the common building design software and structural analysis software. As can be seen from the table, the international general structure analysis software IFC structure analysis model is poor; it is difficult to meet the requirements of seismic analysis of structures.

TABLE II. IFC Model of ARChitectural Design Software AND STRUCTURAL ANALYSIS SOFTWARE

\begin{tabular}{|c|c|c|c|c|c|c|}
\hline $\begin{array}{c}\text { Testing } \\
\text { Software }\end{array}$ & $\begin{array}{c}\text { Geometric } \\
\text { properties }\end{array}$ & $\begin{array}{c}\text { Material } \\
\text { properties }\end{array}$ & $\begin{array}{c}\text { Structural } \\
\text { analysis } \\
\text { model } \\
\text { entity }\end{array}$ & $\begin{array}{c}\text { Reinforcement } \\
\text { information }\end{array}$ & Load & $\begin{array}{c}\text { Support } \\
\text { constraint }\end{array}$ \\
\hline $\begin{array}{c}\text { Revit } \\
\text { Structure } \\
2013\end{array}$ & $\sqrt{ }$ & $\sqrt{ }$ & $\times$ & $\times$ & $\times$ & $\times$ \\
\hline Etabs & $\sqrt{ }$ & $\times$ & $\sqrt{ }$ & $\times$ & $\times$ & $\times$ \\
\hline ArchiCAD & $\sqrt{ }$ & $\sqrt{ }$ & $\times$ & $\times$ & $\times$ & $\times$ \\
\hline SAP2000v15 & $\sqrt{ }$ & $\times$ & $\times$ & $\times$ & $\times$ & $\times$ \\
\hline $\begin{array}{c}\text { Tekla } \\
\text { Structures } \\
18.1\end{array}$ & $\sqrt{ }$ & $\sqrt{ }$ & $\times$ & $\sqrt{ }$ & $\times$ & $\times$ \\
\hline
\end{tabular}

\section{Advantages of Structural Design Methods}

\section{1) High model utilization rate:}

In the traditional design, structural engineers use different software to analyze and compare, need to re modeling, input load, etc., take up a lot of structural division of the analysis of energy, and reduce the analysis efficiency. Based on the BIM platform software can realize the model other exchange, such a structure engineer of structural analysis can be more time in the analysis of parameter adjustment and the comparison in order to derive more reasonable result. It is more prominent in the structural analysis of complex buildings and high-rise buildings.

2) High accuracy of construction drawings:

First, structure model based on the R software is in the building model of the contours of the extracted geometric model is modified by, so as to avoid due to the different design of 2D drawings understanding different degree caused by the deviation. Followed by the final construction drawing is the structure of professional and other equipment after the collision analysis of professional analysis of the audit model. Wall reserved hole, Liang Kaikong and other parts of the need to strengthen the reinforcement and other issues in the construction drawing stage can be a good solution. Finally, for the bending, shear, torsion and other complex components of the reinforcement, can be combined with the use of three-dimensional visualization of the characteristics of BIM platform, three-dimensional reinforcement guidance.

\section{3) High reliability of the calculation results:}

The structure model based on Revit can be introduced into the finite element software with the corresponding data interface, and the calculation results are checked by using different finite element software. According to the analysis model and the actual structure, the structural engineer can determine the reliability of the software calculation and analysis, and then compare and select the reasonable results.

\section{CONCLUSION AND EXPECTATION}

In this paper, the characteristics of Revit structure modeling are analyzed deeply, and it is suggested that the structural engineers use BIM platform to carry out structural modeling. Detailed Revit modeling has the advantages of visualization, collaborative design and parameter driven model. At the same time, the structure analysis software based on Revit structure model is analyzed, and the method of how to use BIM to carry on the analysis and design of anti earthquake structure is introduced in detail.

BIM from the manufacturing industry information management and in the construction industry quickly get recognition and attention. But like $\mathrm{CAD}$, the need for a comprehensive recognition of the construction industry still needs a long period of time. And to meet the BIM standard of domestic software is still in development, the international general BIM core modeling software and the structure calculation software data interface fall far short of the requirements of the BIM platform most of the BIM data exchange.BIM is not only a revolution in the architectural design industry, but also a leap in the management of the construction industry and the way of information transmission.

\section{ACKNOWLEDGMENT}

This work was financially supported by the International Conference on Architectural Engineering and Civil Engineering (AECE2016).

\section{REFERENCES}

[1] Di Ming. Study on urban complex building design theory [J]. Urban construction theory, 2014 (3):1-3.

[2] Qin Lifang. BIM technology in the construction safety management of Hydropower Engineering [D]. Huazhong University of Science and Technology master's thesis, 2013.

[3] Zou Kai. Application examples and techniques [M]. Beijing: China Building Industry Press, 2006.

[4] Autodesk Asia Pte Ltd Autodesk Revitstructure [M]. Shanghai: Tongji University press, 2012.

[5] Liu Zhaoqiu, Li Yungui, Lv Xilin et al. A simplified algorithm and node optimization for intersection relationship of structural components based on boundary representation technology $[\mathrm{J}]$. Journal of building structures, 2010, 31 (9): 58-62.

[6] Zhang Jiantao. Research and application of IFC building international standard [D]. Master Thesis of Beihang University, 2006. 